\title{
Five Cases of an Accessory Left Vertebral Artery on the Aortic Arch
}

\section{Granite $\mathrm{G}^{*}$, Lashley $\mathrm{K}$ and Wind G}

Department of Surgery, Uniformed Services University of the Health Sciences, Bethesda, USA

*Corresponding author: Granite G, PhD, Department of Surgery, Uniformed Services University of the Health Sciences, Bethesda, MD, USA, Tel: 301-295-1500, E-mail: guin.granite@gmail.com

Citation: Granite G, Lashley K, Wind G (2018) Five Cases of an Accessory Left Vertebral Artery on the Aortic Arch. J Case Rep Stud 6(5): 505. doi: 10.15744/2348-9820.6.505

Received Date: September 06, 2018 Accepted Date: October 29, 2018 Published Date: October 31, 2018

\begin{abstract}
Vascular variations of the head and neck are common, but often go unnoticed because they generally do not present clear clinical symptoms. Lack of awareness of the presence and location of such variations may result in iatrogenic complications or even fatalities. Physicians and surgeons should be cognizant of such variations given their potential clinical significance.

Vertebral artery variations are prevalent in both number and origin, but documented infrequently in the literature. Each of the five case studies described here: a White 65-year-old male (Case 1), a White 89-year-old female (Case 2), a White 80-year-old female (Case 3), a White 96-year-old female (Case 4), and a White 95-year-old female (Case 5), presented with an accessory left vertebral artery originating from the aortic arch, between the left common carotid artery and the left subclavian artery. This is the most common place for variations of this type cited in the literature. All five cases in this report, however, also presented with a left vertebral artery branching from the left subclavian artery. For Cases 1 and 3, the accessory left vertebral artery coursed cranially and entered the foramen transversarium at the C5 level. For Case 2, it entered at the C3 level. For Cases 4 and 5, it entered at the C4 level. With a prevalence of $7.81 \%$, among a population of 64 specimens randomly selected and undergoing cadaveric review, this anatomical variant illustrates the potential frequency, and thus, the clinical importance of extensive anatomical understanding of head and neck vascular variations.
\end{abstract}

Keywords: Accessory Left Vertebral Artery; Duplicate Origin of the Left Vertebral Artery; Vertebral Artery Variation; Head and Neck Vascular Variations

\section{Introduction}

Unilateral duplicate origin of the vertebral artery or accessory vertebral artery is considered a rare vascular variant, with a reported incidence between 0.295 and $0.72 \%$ (Figure 1) [1-7]. Considered developmental, this variation shows a dual origin with a variable level of fusion with the vertebral artery (VA) in the neck [1,3,8-11]. Within the literature, we found 57 reported cases involving this vascular variant, with the first reported case in 1844 [3-6,8-10,12-36].

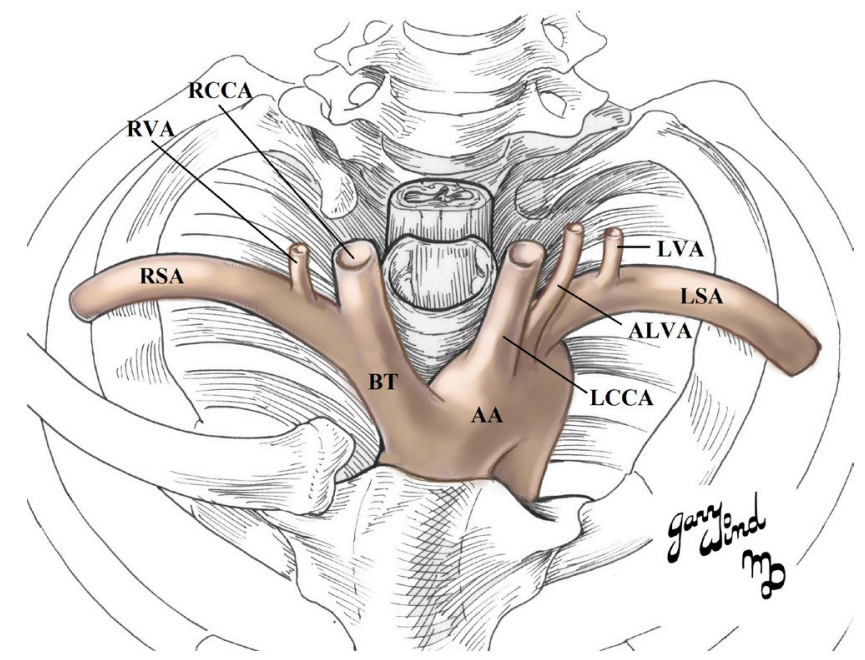

Figure 1: Schematic representation of an accessory right vertebral artery. AA = Aortic Arch; ALVA = Accessory Left Vertebral Artery; LCCA = Left Common Carotid Artery; LSA = Left Subclavian Artery; LVA = Left Vertebral Artery; BT = Brachiocephalic Trunk; RCCA = Right Common Carotid Artery; RSA = Right Subclavian Artery; RVA = Right Vertebral Artery 
Accessory VAs are usually asymptomatic clinically [1,4,7,14,31,37-39]. This origin variation may alter cerebral hemodynamics, however, to cause cerebral dysfunction. Such dysfunction may predispose the individual to certain cerebrovascular pathologies, such as an aneurysm and/or a dissection [4,10,13,22,26,27,38,40-45].

Knowledge of the potential patterns of variant origins for VAs is extremely important when performing both diagnostic and interventional angiography, thoracic surgeries, neurosurgeries, and cardiac catheterization procedures $[1,4,26,38,39,46]$. Such knowledge is even more essential in today's era of carotid and vertebral artery stent placements and new therapeutic options for intracranial interventions $[4,13,32]$. In addition, it is also clinically significant to be aware of VA variations, specifically accessory VAs, since they can be mistaken for a dissection of the VA $[3,10,13,22]$.

\section{Materials and Methods}

Specimens for cadaveric review were provided by the Maryland State Anatomy Board and private donations to the Anatomy Teaching Lab of the Uniformed Services University of the Health Sciences. Anatomy faculty discovered the first of the five accessory left vertebral artery (ALVA) cases (Case 2) when creating a prosection for students enrolled in the Cardiopulmonary-Renal module of the gross anatomy course for first year medical students. Following that discovery, the faculty notified the students and told them to carefully examine their cadavers for any such variations. When such a variation was discovered, the faculty verified its existence and assisted the students with their dissection of the region. One of the five student cadavers (Case 1) was replaced to allow faculty to perform an in-depth dissection and vasculature analysis of the entire head and neck, similar to the analysis performed in Case 2. The other three cadavers could not be replaced. The brains from Cases 3 and 4 were unavailable for study due to their lack of complete fixation during the embalming process. Case 5 involved careful faculty dissection.

To trace the ALVA and left vertebral artery (LVA) accurately, and identify any variations involving the right VA (RVA), we conducted extensive dissections of the entire cervical vertebral column and cranium. First, we removed the sternocleidomastoid and trapezius muscles, as well as all of the infrahyoid muscles of the neck. We detached the superior and inferior thyroid vessels from their attachments to the thyroid gland. This enabled us to remove the trachea and esophagus from C1 to C6 and the thyroid gland and cartilage without destroying any of the external carotid branches. We removed the calvaria and made a trapezoidalshaped wedge in the occipital bone to just above $\mathrm{C} 1$. This enabled us easy access to the base of brain to follow the route of the LVA and RVA as they entered the foramen magnum. Next, we removed all of the deep posterior neck muscles from C1 to C6 to expose the cervical vertebral column. We then performed a laminectomy to reveal the spinal cord from the posterior aspect of $\mathrm{C} 1$ to C6. Following the laminectomy, we removed all of the dorsal portions of the transverse processes from C1 to C6 in a piecemeal progression. This exposed the spinal nerves, LVA, RVA, and the ALVA. We then proceeded to remove the spinal nerves to visualize the VAs better (Figures $2 \mathrm{a}$ and $\mathrm{b}$ ).

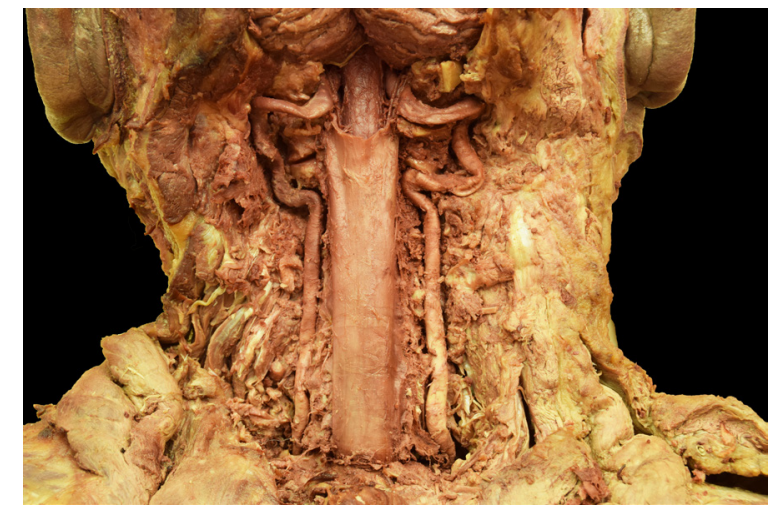

Figure 2a: Case 1: Posterior aspect of deep neck. Posterior and lateral aspects of the cervical vertebrae and spinal nerves were removed to visualize the VAs better. Note the difference in diameter between the LVA and RVA

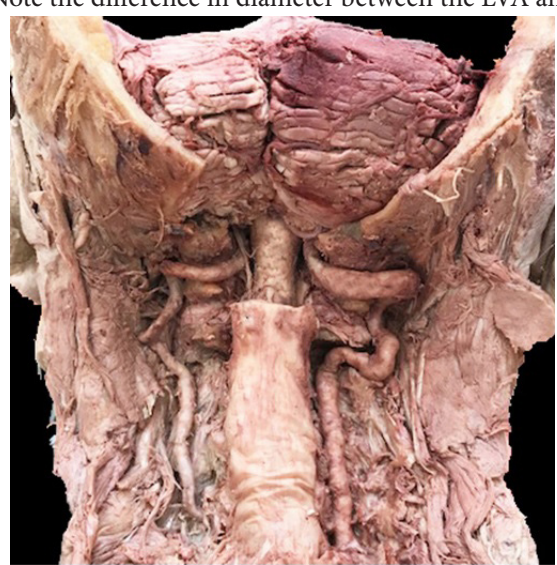

Figure 2b: Case 2: Posterior aspect of deep neck. Posterior and lateral aspects of the cervical vertebrae and spinal nerves were removed to visualize the VAs better. Note the difference in diameter between the LVA and RVA 
From the anterior aspect of the neck, we removed the ventral portions of the transverse processes of C1 to C6. This revealed the path of the ALVA and LVA after they entered the foramen transversaria at different levels.

For Cases 1, 2, and 5 after completely exposing the ALVA, LVA, and RVA, we removed each cadaver's brain, lifting it up and out posteriorly from the cranial vault. This allowed us to maintain the vascular integrity of its blood supply. We then turned over each brain so we could accurately evaluate the circle of Willis and cerebellar and brainstem vasculature to determine if there were any additional vascular variations (Figure $3 \mathrm{a}$ and b). For Cases 3 and 4 , the brain had been removed and disposed of prior to discovery of the ALVA.

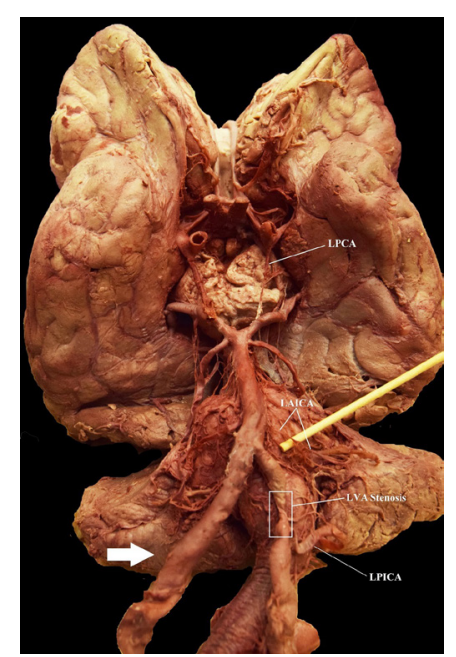

Figure 3a: Case 1: The Circle of Willis, brainstem, and cerebellar vasculature. LAICA = Left Anterior Inferior Cerebellar Artery; LPCA = Left Posterior Communicating Artery; LPICA = Left Posterior Inferior Cerebellar Artery; LVA = Left Vertebral Artery; RAICA = Right Anterior Inferior Cerebellar Artery. The white arrow shows the absence of Right Posterior Inferior Cerebellar Artery

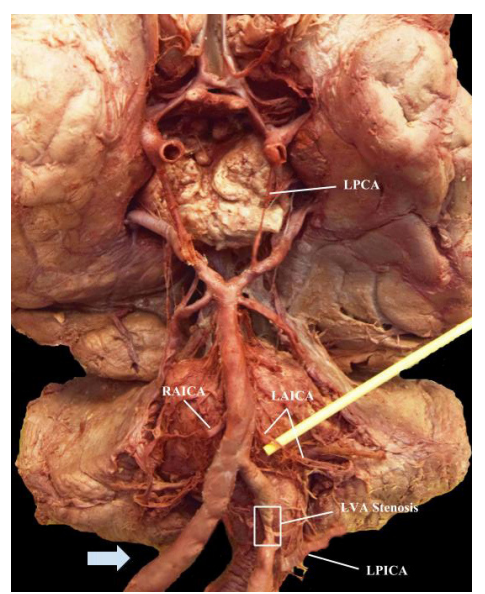

Figure 3b: Case 1: Extended view of the Circle of Willis, brainstem, and cerebellar vasculature. LAICA = Left Anterior Inferior Cerebellar Artery; LPCA = Left Posterior Communicating Artery; LPICA = Left Posterior Inferior Cerebellar Artery; LVA = Left Vertebral Artery; RAICA $=$ Right Anterior Inferior Cerebellar Artery. The white arrow shows the absence of Right Posterior Inferior Cerebellar Artery

\section{Results}

The five cases presented here: a White 65-year-old male with a cause of death (COD) of chronic obstructive pulmonary disease (COPD) (Case 1), a White 89-year-old female with a COD of dementia (Case 2), a White 80-year-old female with a COD of ischemic myopathy and coronary artery disease (CAD) (Case 3), a White 96-year-old female with a COD of dementia (Case 4), and a White 95-year-old female with a COD of acute kidney failure (Case 5) involved an accessory left VA (ALVA) originating directly from the arch of the aorta, between the left common carotid artery (LCCA) and the left subclavian artery (LSA), in addition to a left vertebral artery (LVA) branching off the LSA. These five instances of an accessory VA detected during our cadaveric review of 64 specimens, demonstrated a prevalence of $7.81 \%$.

In four of the five cases, while performing superior mediastinal cadaveric dissections, we uncovered a fourth branch of the aortic arch (AA). In Case 5, we also uncovered a fifth branch: a retroesophageal right subclavian artery (RSA). Upon further investigation of all five cases, we observed that the fourth branch vascular variation was an ALVA, emerging between the LCCA and LSA. With further dissection cranially along the LSA, we also found a LVA of normal diameter serving as the first branch of the LSA in Cases 1,3 , and 4, and a hypoplastic LVA in Cases 2 and 5. 


\section{Case 1}

The RVA exhibited no anatomical variations. It branched from the right subclavian artery (RSA), traveling medially and entered the foramen transversarium at the C6 level. On the left side, the ALVA accompanied a normal LVA. The ALVA originated directly from the arch of aorta, between the LCCA and the LSA. The LVA mimicked the RVA, branching from the LSA and travelling medially to enter the C6 foramen transversarium. The ALVA entered the foramen transversarium slightly higher at the C5 level. It traveled vertically, where it united with the LVA to form a single vessel before entering the C4 foramen transversarium. At this junction, the ALVA also had a small radiculomedullary artery (RMA) branch that traveled medially and entered the vertebral body between the C4 and C5 vertebral bodies (Figure 4). As the LVA ascended toward the brain, it exhibited stenosis (hypoplasia) after the origin of the left posterior inferior cerebellar artery (LPICA) branching before its convergence with the RVA to create the basilar artery (Figures $3 a$ and b, Table 1). The circle of Willis and cerebellum also demonstrated some vasculature variations (Figures $2 \mathrm{a}$ and $2 \mathrm{~b}$, Table 1). The right posterior inferior cerebellar artery (RPICA) was absent on the circle of Willis. The left anterior inferior cerebellar artery (LAICA) and left posterior communicating artery (LPCA) were both hypoplastic, with an enlarged LPICA (Figure 2b, Table 1).
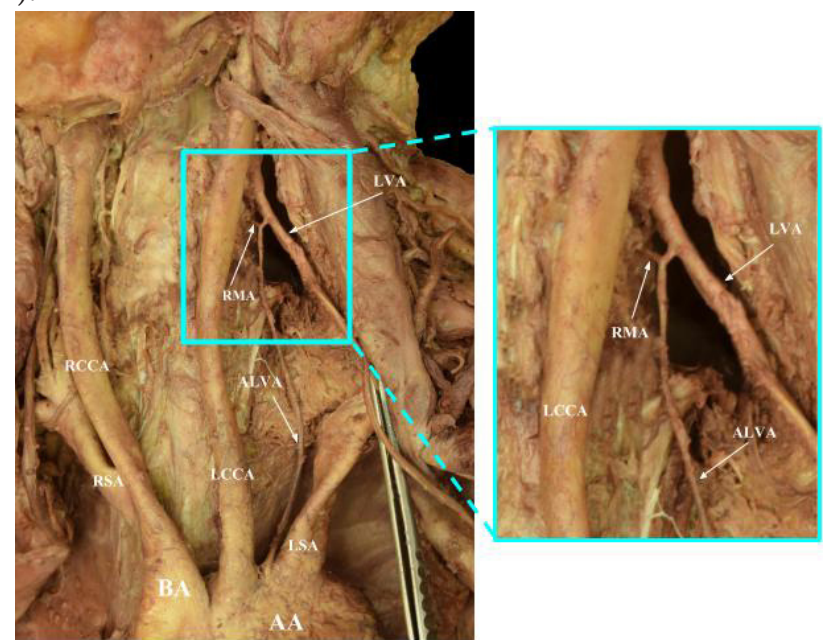

Figure 4: Case 1: Before ALVA merges with LVA, a radiculomedullary artery branch travels medially and between C5 and C6. Lateral aspects of cervical vertebrae have been removed for ease of visualization. AA $=$ Aortic Arch; ALVA = Accessory Left Vertebral Artery; BT = Brachiocephalic Trunk; LCCA = Left Common Carotid Artery; LSA = Left Subclavian Artery; LVA = Left Vertebral Artery; RCCA = Right Common Carotid Artery; RMA = Radiculomedullary Artery; RSA = Right Subclavian Artery

\begin{tabular}{|c|c|c|c|c|}
\hline Case & Ethnicity/Sex/Age & Cause of Death & LVA/ALVA Variation & Circle of Willis Variation \\
\hline 1 & White/Male/65 & $\begin{array}{l}\text { Chronic Obstructive } \\
\text { Pulmonary Disease }\end{array}$ & $\begin{array}{l}\text { Hypoplastic ALVA } \\
\text { coming off AA between } \\
\text { LCCA \& LSA; LVA } \\
\text { coming off LSA }\end{array}$ & $\begin{array}{l}\text { RPICA absent; hypoplastic LAICA } \\
\text { and LPCA; enlarged LPICA; areas of } \\
\text { stenosis on LVA after origin of LPICA } \\
\text { and before converging with RVA to } \\
\text { create basilar artery }\end{array}$ \\
\hline 2 & White/Female/89 & Dementia & $\begin{array}{c}\text { ALVA coming off AA } \\
\text { between LCCA \& LSA; } \\
\text { Hypoplastic LVA coming } \\
\text { off LSA }\end{array}$ & Hypoplastic RPoCA and LPCA \\
\hline 3 & White/Female/80 & $\begin{array}{c}\text { Ischemic Myopathy; } \\
\text { Coronary Artery } \\
\text { Disease }\end{array}$ & $\begin{array}{l}\text { Hypoplastic ALVA } \\
\text { coming off AA between } \\
\text { LCCA \& LSA; LVA } \\
\text { coming off LSA }\end{array}$ & $\begin{array}{l}\text { Could not evaluate; brain was not } \\
\text { completely embalmed }\end{array}$ \\
\hline 4 & White/Female/96 & Dementia & $\begin{array}{l}\text { ALVA coming off AA } \\
\text { between LCCA \& LSA; } \\
\text { LVA coming off LSA }\end{array}$ & $\begin{array}{l}\text { Could not evaluate; brain was not } \\
\text { completely embalmed }\end{array}$ \\
\hline 5 & White/Female/95 & Acute Kidney Failure & $\begin{array}{l}\text { ALVA coming off the } \\
\text { AA between LCCA; } \\
\text { hypoplastic LVA coming } \\
\text { off LSA; Retroesophageal } \\
\text { RSA ( } 5 \text { branches off AA) }\end{array}$ & $\begin{array}{l}\text { Slightly hypoplastic RPCA; LPCA } \\
\text { markedly dilated, and the RVA has an } \\
\text { area of stenosis just before it joins the } \\
\text { ALVA to become the basilar artery }\end{array}$ \\
\hline
\end{tabular}

Table 1: List of case descriptions included in this article; AA = Aortic Arch; ALVA = Accessory Left Vertebral Artery; LAICA = Left Anterior Inferior Cerebellar Artery; LCCA = Left Common Carotid Artery; LPCA = Left Posterior Communicating Artery; LPICA = Left Posterior Inferior Cerebellar Artery; LSA = Left Subclavian Artery; LVA = Left Vertebral Artery; RPICA = Right Posterior Inferior Cerebellar Artery; RPoCA = Right Posterior Cerebral Artery; RSA = Right Subclavian Artery

The dimensions of the ALVA were as follows: diameter $1.25 \mathrm{~mm}$ and length $10.7 \mathrm{~cm}$. The LVA had a diameter of $6 \mathrm{~mm}$ and the RVA had a diameter of $7 \mathrm{~mm}$. The ALVA demonstrates hypoplasia since its diameter was less than $2.5 \mathrm{~mm}$ [39]. 


\section{Case 2}

The RVA, with a diameter of $5.5 \mathrm{~mm}$, exhibited no anatomical variations. It branched from the RSA, traveling medially and entering the foramen transversarium at the C5 level. On the left side, there was an ALVA and a hypoplastic LVA (diameter 1 mm). The ALVA, which served as the main conduit for blood from the aorta to the brain on the left side, originated directly from the AA, between the LCCA and the LSA. The ALVA diameter was not consistent throughout, ranging from 2.5-3.5 mm and containing areas of narrowing. The arterial branching for LSA was displaced inferiorly, branching earlier on the LSA than is typically observed. For example, the hypoplastic LVA branched off at the T2 level (Figure 5, Table 1).

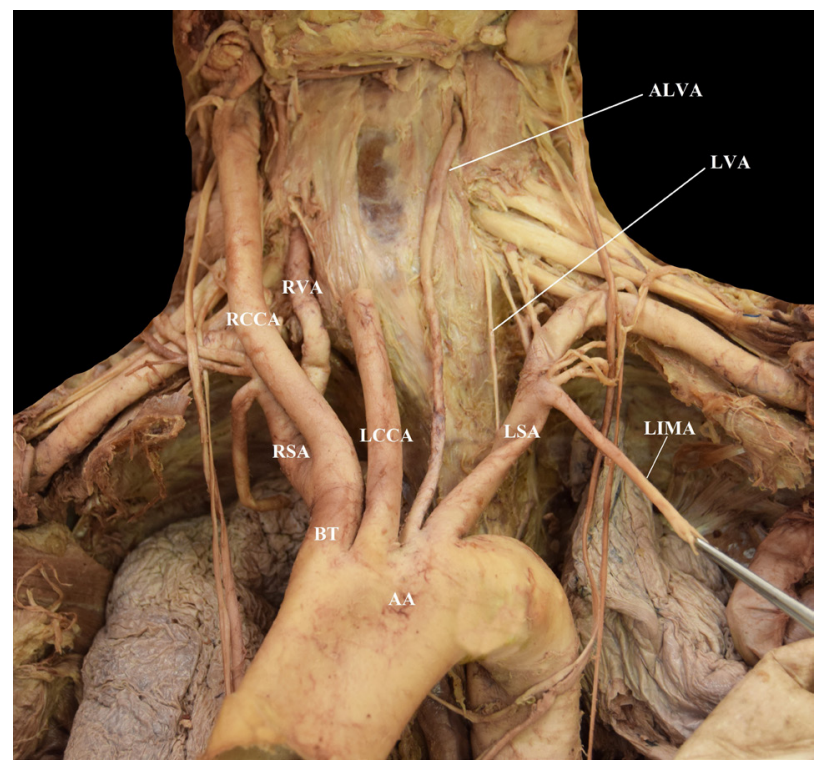

Figure 5: Case 2: LCCA was bisected with its superior portion reflected cranially and the LIMA was given tension laterally with forceps for LVA and ALVA visibility. AA = Aortic Arch; ALVA = Accessory Left Vertebral Artery; BT = Brachiocephalic Trunk; LCCA = Left Common Carotid Artery; LSA = Left Subclavian Artery; LVA = Left Vertebral Artery; RCCA = Right Common Carotid Artery; RSA = Right Subclavian Artery

The ALVA entered the foramen transversarium at the C3 level; higher than the LVA, which entered at C6. Prior to uniting with the ALVA within the $\mathrm{C} 2$ foramen transversarium, the LVA had a small RMA branch that traveled medially, entering either the C3 and/or C4 vertebral bodies (Figure 6, Table 1). As the ALVA ascended toward the brain, it exhibited areas of stenosis or hypoplasia. These occurred just before joining the RVA to create the basilar artery ( $1.5 \mathrm{~mm}$ diameter). A $1.3 \mathrm{~cm}$ section the ALVA was 2.5 $\mathrm{mm}$ in diameter just before the LPICA branch formed. The circle of Willis and cerebellum also demonstrated some vasculature variations. The right posterior cerebral artery (RPoCA) and left posterior communicating artery (LPCA) of the circle of Willis were hypoplastic (0.5 $\mathrm{mm}$ in diameter for both) (Figure 7, Table 1).

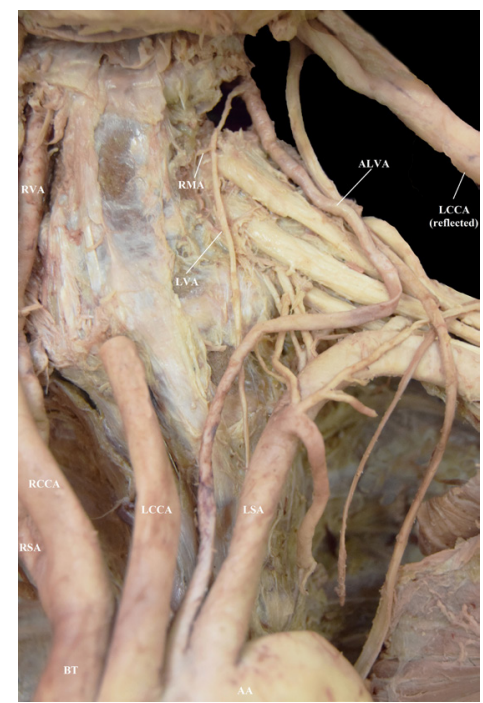

Figure 6: Case 2: Before LVA merges with ALVA, a radiculomedullary artery branch travels medially and between C3 and C4. Lateral aspects of cervical vertebrae have been removed, as well as the LCCA was bisected and reflected for ease of visualization. AA = Aortic Arch; ALVA = Accessory Left Vertebral Artery; BT = Brachiocephalic Trunk; LCCA = Left Common Carotid Artery; LSA = Left Subclavian Artery; LVA = Left Vertebral Artery; RCCA = Right Common Carotid Artery; RMA = Radiculomedullary Artery; RSA = Right Subclavian Artery 


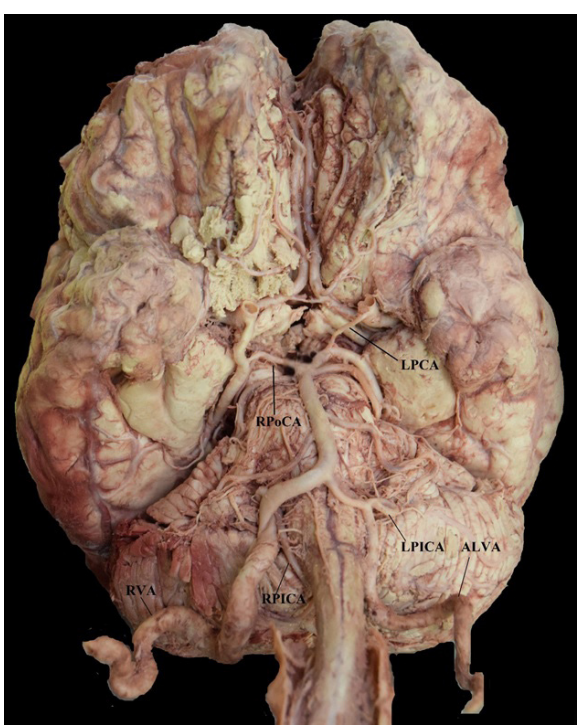

Figure 7: Case 2: The Circle of Willis, brainstem, and cerebellar vasculature. ALVA = Accessory Left Vertebral Artery; LPCA = Left Posterior Communicating Artery; LPICA = Left Posterior Inferior Cerebellar Artery; RPICA = Right Posterior Inferior Cerebellar Artery; RPoCA = Right Posterior Cerebral Artery; RVA = Right Vertebral Artery

\section{Case 3}

The RVA exhibited areas of stenosis, with a diameter ranging between 3 and $5.5 \mathrm{~mm}$. It branched from the RSA and traveled medially to enter the foramen transversarium at the C6 level. The LVA also demonstrated areas of stenosis and entered the foramen transversarium at the C6 level. Its diameter was $3.5-5.25 \mathrm{~mm}$. The ALVA originated directly from the AA, between the LCCA and the LSA. It was hypoplastic ( $0.5 \mathrm{~mm}$ diameter) and entered the foramen transversarium just above the LVA at the C5 level. The length of the ALVA was $10.3 \mathrm{~mm}$ before uniting with the LVA. Just before merging with the LVA, the ALVA had a small RMA branch that travelled medially and entered either the C5 and/or C6 vertebral bodies (Table 1). Further, dissection of vessel architecture beneath the brain was precluded by the lack of complete fixation during embalming.

\section{Case 4}

Both the RVA and LVA entered the foramen transversarium at the C6 level. The RVA exhibited areas of stenosis, with a diameter ranging between 3 and $5.5 \mathrm{~mm}$. The LVA had a diameter of $3 \mathrm{~mm}$. The ALVA also demonstrated areas of stenosis, with a diameter ranging between $2.5-3.5 \mathrm{~mm}$. It originated from a common branch with LSA from the aorta and entered the foramen transversarium at the level of C4. It served as the main conduit for blood from the aorta to the brain on the left side. Before merging with the ALVA within the C4 foramen transversarium, the LVA ( $8.8 \mathrm{~mm}$ length) had a small RMA branch that traveled medially and entered either the $\mathrm{C} 4$ and/or C5 vertebral bodies (Figure 8, Table 1). Further, dissection of vessel architecture beneath the brain was precluded by the lack of complete fixation during embalming.

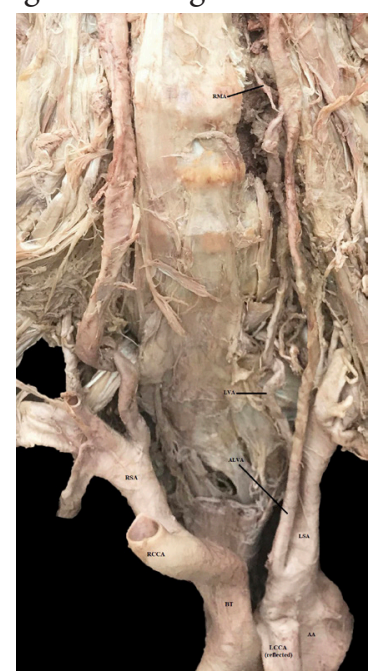

Figure 8: Case 4: Before ALVA merges with LVA, a radiculomedullary artery branch travels medially and between C4 and C5. Lateral aspects of cervical vertebrae have been removed, as well as the LCCA was bisected and reflected for ease of visualization. AA = Aortic Arch; ALVA = Accessory Left Vertebral Artery; BT = Brachiocephalic Trunk; LCCA = Left Common Carotid Artery; LSA = Left Subclavian Artery; LVA = Left Vertebral Artery; RCCA = Right Common Carotid Artery; RMA = Radiculomedullary Artery; RSA = Right Subclavian Artery 


\section{Case 5}

There were five branches from the AA: LSA, LCCA, ALVA, retroesophageal subclavian artery (RRSA), and a right brachiocephalic trunk (RBT) variation. The branches of the RBT were the right common carotid artery (RCCA) and the RVA. Both the RVA and ALVA entered the foramen transversarium at the C4 level, while the LVA entered at the C6 level. The RVA had a diameter of 3.5 $\mathrm{mm}$. The LVA was hypoplastic, with a diameter of $1 \mathrm{~mm}$. As the LVA traveled cranially, it gave off two small RMA branches before merging with the ALVA. The first RMA traveled medially and entered either the C5 and/or C6 vertebral bodies, and the second RMA entered between C4 and C5 (Figure 9, Table 1). The length of the LVA was $5.4 \mathrm{~cm}$ before uniting with the ALVA within the C4 foramen transversarium. As the ALVA ascended cranially, it exhibited stenosis with a diameter ranging between 4 and 5 mm. The circle of Willis also demonstrated some anomalies: the right posterior communicating artery (RPCA) was slightly hypoplastic while the LPCA was markedly dilated. The RVA had an area of stenosis just before it joined the ALVA to become the basilar artery (Figure 10, Table 1).

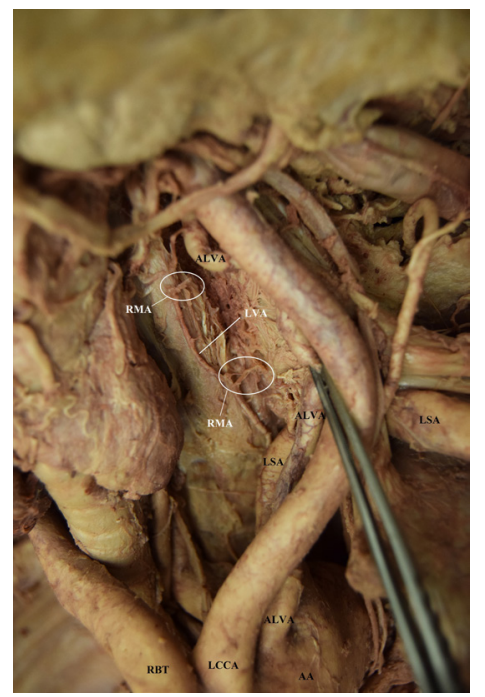

Figure 9: Case 5: Before LVA merges with ALVA, two radiculomedullary artery branches travel medially and between C4 and C5, and C5 and C6. Lateral aspects of cervical vertebrae have been removed, as well as the LCCA and ALVA pulled laterally with forceps for ease of visualization. AA = Aortic Arch; ALVA = Accessory Left Vertebral Artery; LCCA = Left Common Carotid Artery; LSA = Left Subclavian Artery; LVA = Left Vertebral Artery; RBT = Right Brachiocephalic Trunk; RMA = Radiculomedullary Artery

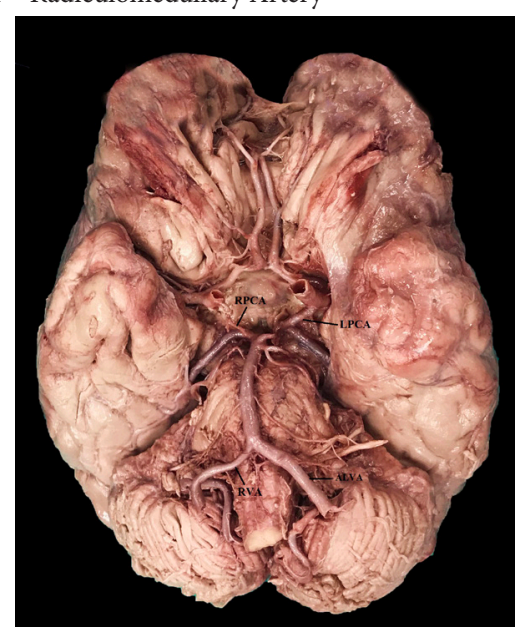

Figure 10: Case 5: The Circle of Willis, brainstem, and cerebellar vasculature. LPCA = Left Posterior Communicating Artery; LVA = Left Vertebral Artery; RPCA = Right Posterior Communicating Artery; RVA = Right Vertebral Artery

\section{Discussions}

The literature contains various descriptions of anomalous origins of the vertebral artery. These include a left vertebral artery branching directly off the AA between the LCCA and LSA; a LVA branching directly off the AA distal to the LSA; duplicate origin of or an accessory VA; an origin of the VA from the innominate, common carotid, or external carotid arteries; and a persistent proatlantal or hypoglossal artery that connects the internal carotid artery to the VA [5,15,19,30,47-49]. Left unilateral accessory VAs are observed more commonly than right $[5,9,44,50]$. In most cases, the accessory VA arises from the AA or the subclavian artery. Other less common sites of origin are the common carotid artery, brachiocephalic trunk (BT), or thyrocervical trunk $[2,3,26]$. Accessory VAs usually enter at a higher foramen transversarium than the VA, which almost invariably enters at the C6 foramen transversarium [1,3,22]. The documented frequency of accessory VAs is $0.295-0.72 \%$ [1,6,7]. Bilateral duplication of the VAs is extremely rare, with only three cases reported in literature $[3,4,8,24,26]$. 
Duplications of or accessory VAs have been mistaken for a similar type of VA vasculature variants known as fenestrations of the VA $[3,4,10]$. Fenestration or partial duplication of the VA results from a single origin that splits to form two channels that later rejoin distally $[3,9,11,22]$. Fenestration of the VA has been shown angiographically in the more current literature but has also been mentioned historically in 1866 [51]. It is most commonly seen in the extracranial VA segments [11,51-53]. Autopsy and angiographic studies indicate an incidence of VA fenestration of $0.23 \%-1.90 \%$. VA fenestration is associated frequently with intracranial vascular abnormalities [11,27,53,54].

Accessory VAs are developmental variants that result from a failure of fetal vessel involution $[4,7,10]$. Initially, the embryo has two dorsal aortas that communicate with an aortic sac via six sets of matched aortic arches. These matching aortic arches undergo selective apoptosis. The residual branch vessels constitute the AA and great vessels. The right dorsal aorta largely regresses. The first, second, and fifth aortic arches also regress. The third aortic arches participate in the formation of the common and proximal internal carotid arteries bilaterally. The left fourth arch artery becomes part of the AA between the origin of the LCCA and the LSA, while the right fourth arch artery persists as the root of the RSA. The aortic sac evolves into the brachiocephalic artery and AA. The sixth arch forms the pulmonary arch, which develops into the right pulmonary artery and ductus arteriosus. The left dorsal aorta creates the AA between the ductus arteriosus and the LSA. The fused right and left dorsal aortae create the AA distal to the left subclavian artery (Figure 11) $[11,32,42,46]$.

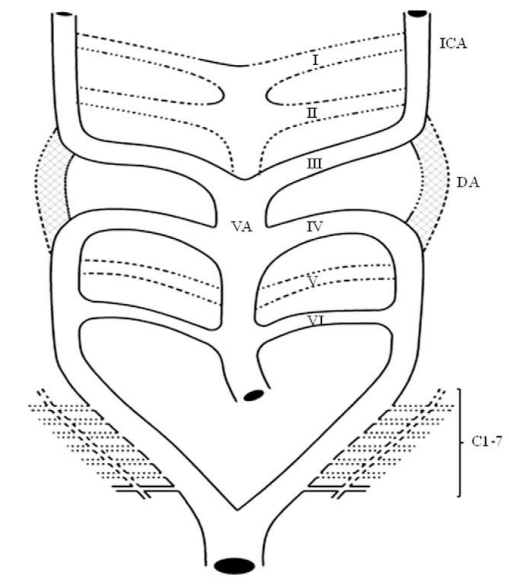

Figure 11: Schematic representation of the supra aortic arteries at $\sim 4$ gestational weeks. Reprinted from Cheng et al. (2009). DA = dorsal aorta; ICA $=$ internal carotid artery; IeVI = aortic arches IeVI; VA = ventral aorta

The VAs arise between embryonic days 33 and 35 [7] by the fusion of the postcostal longitudinal anastomoses that link the cervical intersegmental arteries. These intersegmental arteries branch from the primitive paired dorsal aorta (Figure 12). Eventually, all but the seventh of these intersegmental arteries are obliterated $[1,10,13,14,38,46,48,50,55]$. The left seventh intersegmental artery persists to become the entire proximal LSA to the level of the internal thoracic artery. The right seventh intersegmental artery forms the distal one-third of the proximal RSA [46]. The proximal subclavian arteries also include the VA point of origin in studied adults $[10,46,48]$.

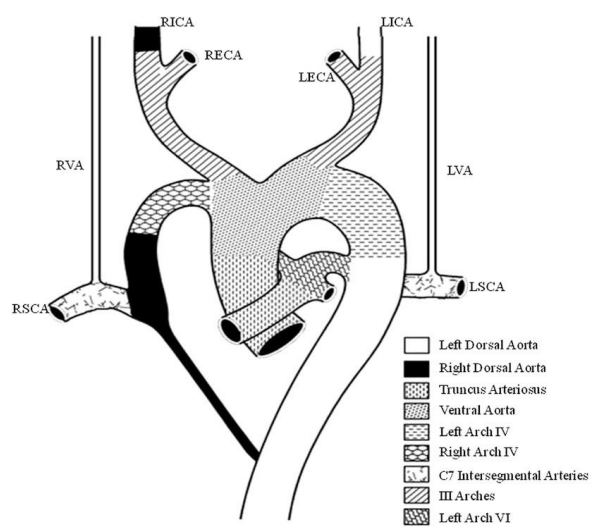

Figure 12: Schematic representation of the supra-aortic arteries at 7 weeks of development. Reprinted from Cheng et al. (2009). LECA = left external carotid artery; LICA = left internal carotid artery; LSCA = left subclavian artery; LVA = left vertebral artery; RECA = right external carotid artery; RICA = right internal carotid artery; RSCA = right subclavian artery; RVA = right vertebral artery

Accessory VAs result from a developmental variation of the AA and the persistence of intersegmental arteries [46,56]. For accessory RVAs (ARVAs), originating from the RSA or BT, the right fourth, fifth or sixth (or less frequently third) intersegmental artery persists. For the ALVA, the left fourth, fifth or sixth (or less frequently third) the intersegmental artery persists [1,3,26,30,44]. Additionally, the level at which the accessory VA enters the foramen transversarium indicates which intersegmental artery or arteries persist $[3,4,13,23,27]$. In the cases presented here, we propose that the left fifth intersegmental artery persisted for Cases 1 and 3, the left third intersegmental artery persisted for Case 2, and the left fourth intersegmental artery persisted for Cases 4 and 5. 
Hypoplasia of VA is common. Hypoplasia occurs when the diameter of the VA on one side of the body is less than $50 \%$ of the contralateral side or its diameter is less than $2.5 \mathrm{~mm}$ [39]. In Case 1, the diameter of the ALVA was $1.25 \mathrm{~mm}$. In cases 2 and 5 , the LVA diameter was $1 \mathrm{~mm}$. In Case 3, the ALVA diameter was $0.5 \mathrm{~mm}$. The presence of hypoplasia the ALVA has been documented in the literature; a contributing branch may arise from the LSA or the LVA and not the ALVA [27,46]. The course of the ALVA for each of presented cases, however, was consistent with the published literature. The ALVA coursed through the foramen transversarium above the LVA origin, which in each of the five cases, was at C6. Other literature also states that the ALVA generally enters through the fifth, the fourth, or even the seventh, other than the sixth vertebra [39]. In each case, except Case 2, the ALVA traveled through the C4 or C5 foramen transversarium. In Case 2, it entered at the C3 foramen transversarium.

Clinically, accessory VAs are non-specific and usually asymptomatic $[1,3,14]$. Whether accessory VAs associated with pathological conditions remains controversial. Ionete and Omojola [8] demonstrated that accessory VAs were normal variations discovered incidentally with no significant pathological or clinical symptomology $[8,13,14]$. Conversely, numerous anecdotal reports state that this vascular variant may predispose the patient to VA dissection, intracranial aneurysm, kinking, and arteriovenous malformations since these variants are often associated with significant cerebrovascular abnormalities [4,10,22,26,38,40-43]. In addition, anecdotal reports describe clinical symptoms, such as dizziness or vertigo in patients with anomalous origins of VA $[1,4,7,24,26,28,34,42]$. Furthermore, when the ALVA serves as an additional point of attachment of the VA, it predisposes individuals to more serious outcomes from contusions that commonly may occur during motor vehicle accidents [1].

Without conclusive histological data about accessory VAs, VAs has been described with fenestrations. Fenestrations commonly accompany differences in thickness and composition of the vessel walls with media defects histologically. This predisposes individuals to aneurysm development [22]. With such similar vascular characteristics, these anatomical variants could predispose individuals to vertebral cervical arterial dissection (CAD), via local histological defects or significant hemodynamic alterations $[10,11,14,40]$.

Accessory VAs are usually diagnosed coincidentally during imaging studies. Thus, awareness of their potential existence is still very important clinically. Such detailed knowledge can prevent iatrogenic injuries during surgery, inadvertent diagnostic or therapeutic challenges during endovascular, thoracic, and/or neurologic procedures. In addition, due to the common smaller lumen size of accessory VAs and their entrance at a higher foramen transversarium level than their associated VAs, their locations can influence the choice or route of surgical treatment $[3,8,14,22,26,38,42,50]$.

The vascular variances exhibited with the circle of Willis and cerebellum in these five cases are well-documented in the literature. The PICA can be absent unilaterally [57]. Hypoplasia is one of the most frequent vascular anomalies in the circle of Willis, ranging from a 23-27\% incidence [58-61]. Circle of Willis arteries that are less than $1 \mathrm{~mm}$ in external diameter are considered hypoplastic, with the exception of the communicating arteries. These are considered hypoplastic when diameters are less than $0.5 \mathrm{~mm}[58,60]$. The size of the AICA is usually inversely related to the size of the PICA. When the AICA is hypoplastic, the ipsilateral PICA is usually larger and supplies the area of the hypoplastic AICA [62]. Posterior communicating artery variations are among the most common, with hypoplasia observed in 12 to $60 \%$ of researched samples, followed by posterior cerebral artery in $10 \%$ [63]. The association between circle of Willis anomalies and cerebral aneurysms is well-documented [58,64]. Such variations may contribute to the dizziness and vertigo that some individuals experience.

\section{Conclusions}

Head and neck arterial vascular variations are common and occur naturally. Due to the compensatory effects, most of these variations have no overt influence on blood supply, presenting usually only during imaging studies or cadaveric dissection. Accordingly, most accessory VA cases described in the literature did not result in clinical symptoms [3,39,55]. Some authors, however, have hypothesized that anomalous origins of the VA, particularly from the AA, can cause modifications in cerebral hemodynamics. This may predispose a patient to aneurysms, VA dissection, and arteriovenous malformations, increasing the risk of a cerebrovascular accident $[8,10,22,38,42,46]$. In none of our cases did we detect the presence of aortic aneurysm, which might increase the risk of CVA [46].

Given the age range of the individuals we examined (65 year-old male, 89 year-old female, 80 year-old female, 96 year-old female, 95 year-old female) and the different listed COD (COPD, dementia, ischemic myopathy with CAD, dementia, and acute renal failure), it is likely that their vascular variations were reported as symptomatic during life.

Since such variation is relatively common, multislice computed tomography angiographies (CTAs), MRIs, and/or ultrasounds may be advisable preoperatively to detect and evaluate any such vascular anatomical variations. Understanding the possible vascular variations involving VAs, as well as their embryologic origins, can help to identify unexpected vascular findings when assessing these imaging studies of patients in clinical practice. Additionally, knowledge of vascular variation can assist in effective differentiation of accessory VAs from other pathological conditions, such as VA dissection, and help to avoid iatrogenic injury $[3,10,14,55,65]$. Such evaluations can provide accurate guidance for surgical intervention regarding location, type, and the course of any vascular variations to ensure precise and safe preoperative planning $[39,42]$. 


\section{Acknowledgements}

We would like to thank the families of our donors for their beneficent contribution. Without their generosity, this article would not have been possible. We would also like to thank the class of 2021 medical students, Sarah Hawley, Evan Moore, Max Miller, and Julia Harris, for allowing us to exchange their cadaver for another during their gross anatomy class to perform an in-depth dissection and vasculature analysis of the entire head and neck. Other students continued to analyze the other four remaining cadavers. Dr. Howard Bryant of the Department of Anatomy, Physiology, and Genetics at the Uniformed Services University of the Health Sciences in Bethesda, Maryland provided a critical editorial critique of this manuscript. For that, we are deeply appreciative.

\section{References}

1. Kim MS (2018) Duplicated Vertebral Artery: Literature Review and Clinical Significance. J Korean Neurosurg Soc 61: 28-34.

2. Bergman RA, Thompson SA, Afifi AK, Saadeh FA (1988) Compendium of human anatomic variation: Text, atlas and world literature. Baltimore: Urban and Schwarzenberg. 71-2: 358-9.

3. Baik J, Baek HJ, Shin HS, Choi KH (2016) Duplication of the right vertebral artery: MRA findings and review of the literature. Springer Plus 5: 1123.

4. Gupta OMP, Gupta KK, Qasim M, Rameshbabu CS (2014) Bilateral asymmetrical duplicated origin of vertebral arteries: Multidetector row CT angiographic study. Indian J Radiol Imaging 24: 61-5.

5. Mahmutyazicioğlu K, Saraç K, Bölük A, Kutlu R (1998) Duplicate Origin of Left Vertebral Artery with Thrombosis at the Origin: Color Doppler Sonography and CT Angiography Findings. J Clin Ultrasound 26: 323-325.

6. Polguj M, Jęrdzejewski K, Topol M, Wierczorek-Pastusiak J, Majos A (2013a) Duplication of the left vertebral artery in a patient with dissection of the right internal carotid artery and Ehlers-Danlos syndrome: case report and review of the literature. Anat Sci Int 88: 109-14.

7. Yuan SM (2016) Aberrant Origin of Vertebral Artery and its Clinical Implications. Braz J Cardiovasc Surg 31: 52-9.

8. Ionete C, Omojola MF (2006) MR angiographic demonstration of bilateral duplication of the extracranial vertebral artery: Unusual course and review of the literature. AJNR Am J Neuroradiol 27: 1304-6.

9. Goddard AJ, Annesley-Williams D, Guthrie JA, Weston M (2001) Duplication of the vertebral artery: report of two cases and review of the literature. Neuroradiol J 43: 477-80.

10. Melki E, Nasser G, Vandendries C, Adams D, Ducreux D, et al. (2012) Congenital vertebral duplication: A predisposing risk factor for dissection. J Neurol Sci 314: 161-2.

11. Ozpinar A, Magill ST, Davies JM, McDermott MW (2015) Vertebral Artery Fenestration. Cureus 7: e245.

12. Komiyama M, Nakajima H, Yamanaka K, Iwai Y (1999) Dual origin of the vertebral artery -- case report. Neurol Med Chir (Tokyo) 39: 932-7.

13. Jung S, Jung C, Jung Bae Y, Se Choi B, Hyoung Kim J (2016) Duplicated Origin of the Left Vertebral Artery: A Case Report and Embryological Review. Neurointervention 11: 50-4.

14. Lemke AJ, Benndorf G, Liebig T, Felix R (1999) Anomalous origin of the right vertebral artery: Review of the literature and case report of right vertebral artery origin distal to the left subclavian artery. AJNR Am J Neuroradiol 20: 1318-21.

15. Babin E and Haller M (1974) Correlation between bony radiological signs and dolichoarterial loops of the cervical artery. Neuroradiol J 7: 15.

16. Harada J, Nishijima M, Yamatani K, Endo S, Takaku A (1987) A case of the duplicate origin of right vertebral artery. No Shinkei Geka 15: 321-5.

17. Harnier S, Harzheim A, Limmroth V, Horz R, Kuhn J (2008) Duplication of the common carotid artery and the ipsilateral vertebral artery with a fenestration of the contralateral common carotid artery. Neurol India 56: 491-3.

18. Hashimoto H, Ohnishi H, Yuasa T, Kawaguchi S (1987) Duplicate origin of the vertebral artery: report of two cases. Neuroradiol J 29: 301.

19. Kiss J (1968) Bifid origin of the right vertebral artery. A case report. Radiology 91: 931.

20. Kuwujara H, Aoto K, Uno J (1988) A case of duplicate origin of the left vertebral artery associated with moyamoya disease. Jpn J Clin Med 66: 1174.

21. Mashiyama S, Watanabe T (1989) Duplicate origin of vertebral artery combined with brain tumor [in Japanese]. Jpn J Clin Radiol 34: 727.

22. Thomas AJ, Germanwala AV, Vora N, Prevedello DM, Jovin T, et al. (2008) Dual origin extracranial vertebral artery: Case report and embryology. J Neuroimaging 18:173-6.

23. Meila D, Tysiac M, Petersen M, Theisen O, Wetter A, et al. (2012) Origin and course of the extracranial vertebral artery - CTA findings, association with vascular lesions and embryologic considerations. Clin Neuroradiol 22: 327-33.

24. Mordasisni P, Schmidt F, Schroth G, Remonda L (2008) Asymmetrical bilateral duplication of the extracranial vertebral arteries: Report of a unique case. Eur J Radiol Extra 67: e91-4.

25. Nishijima M, Harada J, Akai T, Endo S, Takaku A (1989) Operative correction of a kinked duplicate origin of the vertebral artery in a patient with dizziness. Case report. Surg Neurol 32: 356 .

26. Rameshbabu CS, Gupta OMP, Gupta KK, Qasim M (2014) Bilateral asymmetrical duplicated origin of vertebral arteries: Multidetector row CT angiographic study Neuroradiol J 24: 61-5.

27. Rieger P, Huber G (1983) Fenestration and duplicate origin of the left vertebral artery in angiography. Report of three cases. Neuroradiol J 25: 45.

28. Shin SW, Park DW, Park CK, Lee YJ, Lee SR (2013) Duplication of the left vertebral artery origin: A case report. J Korean Soc Radiol 68:1-4.

29. Sugita S, Abe T, Okura A, Wantanabe M, Shigemori M (1995) MRI demonstration of double origin of the left vertebral artery: case note. Neuroradiology 37: 295-6.

30. Suzuki S, Kuwabara Y, Hatano R, Iwai T (1978) Duplicate origin of left vertebral artery. Neuroradiol J 15: 27.

31. Takasato Y, Hayashi H, Kobayashi T, Hashimoto Y (1992) Duplicated origin of right vertebral artery with rudimentary and accessory left vertebral arteries. Neuroradiol J 34: 287-9.

32. Watanabe K, Saga T, Iwanaga J, Tabira Y, Yamaki K (2016) A rare case of dual origin of the left vertebral artery without convergence. Folia Morphol (Warsz) 75: $136-42$. 
33. Tobin WO, Killeen R, Kinsella JA, McCabe DJ (2010) Dual origin of the left vertebral artery: Extracranial MRA and CTA findings. J Neurol Sci 298: 150-2. 34. Nakamura M, Saga T, Tetsuka M, Watanabe K, Koga N, et al. (2012) A case of duplicated left vertebral artery and the research of the entrance of the vertebral artery in transverse foramen of cervical vertebra [Japanese]. Kurume igakukai zasshi 75: 25-31.

35. Eisenberg RA, Vines FS, Taylor SB (1986) Bifid origin of left vertebral artery. Radiology 159: 429.

36. Onizuka K, Kurimoto M, Endo S, Akai T, Takaku A (1991) A case of persistent first segmental artery associated with a duplicate origin of vertebral artery. Jpn J Clin Radiol 36: 1707.

37. Alsaif HA and Ramadan WS (2010) An anatomical study of the aortic arch variations. JKAU Med Sci 17: 37-54.

38. Satheesha BN, Sirasanagandla SR, Surekha DS, Deepthinath R, Sudarshan S, Raghu J (2014) Variant Origin of the Left Vertebral Artery from a VertebroSubclavian Trunk Associated with an Unusual Branch Arising from the Brachiocephalic Trunk. J Surg Academia 4: 73-5.

39. Shi S-K (2017) Arterial Vascular Variation of the Head and Neck and Its Clinical Significance. J Neurol Neurophysiol 8: 442-3.

40. Bernardi L and Dettori P (1975) Angiographic study of a rare anomalous origin of the vertebral artery. Neuroradiol J 9: 43-7.

41. Dare AO, Chaloupka JC, Putman CM, Meyer PL, Schneck MJ, et al. (1997) Vertebrobasilar dissection in a duplicated cervical vertebral artery: A possible pathoetiologic association? A case report. Vasc Endovascular Surg 31: 103-9.

42. Satti SR, Cerniglia CA, Koenigsberg RA (2007) Cervical vertebral artery variations: An anatomic study. AJNR Am J Neuroradiol 28: 976-80.

43. Kendi AT, Brace JR (2009) Vertebral artery duplication and aneurysms: 64 slice multidetector CT findings. Br J Radiol 82: e216-8.

44. Komiyama M, Morikawa T, Nakajiman H, Nishikawa M, Yasui T (2001) High incidence of arterial dissection associated with left vertebral artery of aortic origin. Neurol Med Chir (Tokyo) 41: 8-11.

45. Kim DW (2009) Concomitant dual origin and fenestration of the left vertebral artery resembling dissection. J Korean Neurosurg Soc 46: 498-500.

46. Cheng M, Xie X, Wang C, You C, Mao B, He M, Zhang C (2009) Two Anatomic Variations of the Vertebral Artery in Four Patients. Ann Vasc Surg 23: 689.e1-. e5.

47. Ouchi H, Ohara I (1968) Extracranial abnormalities of the vertebral artery detected by selective arteriography. J Cardiovasc Surg 9: 250.

48. Newton TH and Mani RL (1974) The Vertebral Artery In: Newton TH and Potts DG (Eds.) Radiology of the Skull and Brain. Mosby: St. Louis, USA.

49. Kowada M, Yamaguchi K, Takahashi H (1972) Fenestration of the vertebral artery with a review of 23 cases in Japan. Radiology 103: 343.

50. Panicker HK, Tarnekar A, Dhawane V, Ghosh SK (2002) Anomalous Origin of Left Vertebral Artery - Embryological Basis and Applied Aspects - A Case Report. J Anat Soc India 51: 234-5.

51. Kadyi H (1866) Über die Blutgefäße des menschlichen Rükkenmarkes. Anat Anz 1.

52. Krayenbühl H, Yasargil, MG (1957) Die vasculären Erkrankungen im Gebiet der Arteria vertebralis und Arteria Basilaris Stuttgart: Thieme 38.

53. Kowada M, Takahashi M, Gito Y, Kishikawa T (1973) Fenestration of the Vertebral Artery: Report of 2 Cases Demonstrated by Angiography 6: 110-2.

54. Mizukami M, Mine T, Tomita T (1968) Fenestration of the vertebral artery (vertebral diastematoarteria) Coexistence of cerebral aneurysm and cerebral arteriovenous malformation. No To Shinkei 20: 1271-6.

55. Case D, Seinfeld J, Folzenlogen Z, Kumpe D (2015) Anomalous Right Vertebral Artery Originating from the Aortic Arch Distal to the Left Subclavian Artery: a Case Report and Review of the Literature J Vasc Interv Radiol 8: 21-4.

56. Polguj M, Podgórski M, Jędrzejewski K, Topol M, Majos A (2013b) Fenestration and duplication of the vertebral artery: the anatomical and clinical points of view. Clin Anat 26: 933-43.

57. Tubbs RS, Loukas M (2016) Vertebrobasilar arteries In: Bergman’s Comprehensive Encyclopedia of Human Anatomic Variation. Wiley Blackwell: Hoboken, NJ, USA.

58. Iqbal S (2013) A Comprehensive Study of the Anatomical Variations of the Circle of Willis in Adult Human Brains. J Clin Diagn Res 7: 2423-7.

59. Alpers BJ, Berry RG, Paddison RM (1959) Anatomical studies of the circle of Willis in normal brain. Arch Neurol Psychiat 81: 409-18.

60. Kamath S (1981) Observations on the length and diameter of the vessels forming the circle of Willis. J Anat 133: 419-23.

61. Fetterman GH, Moran TJ (1941) Anomalies of the circle of Willis in relation to cerebral softening. Arch Pathol 32: 251-57.

62. Jinkins JR (2000) Superior Cerebellar Artery Variants In: Atlas of Neuroradiologic Embryology, Anatomy, and Variants. Lippincott Williams \& Wilkins: Philadelphia, PA 341, USA.

63. Nordon DG and Rodrigues Junior OF (2012) Variations in the brain circulation - the circle of Willis. J Morphol Sci 29: 243-7.

64. Kayembe K, Sasahara M, Hazama F (1984) Cerebral Aneurysms and variations in the circle of Willis. Stroke 15: 846-50.

65. Provenzale JM, Sarikaya B, Hacein-Bey L,Wintermark M (2011) Causes of misinterpretation of cross-sectional imaging studies for dissection of the craniocervical arteries. AJR Am J Roentgenol 196: 45-52. 


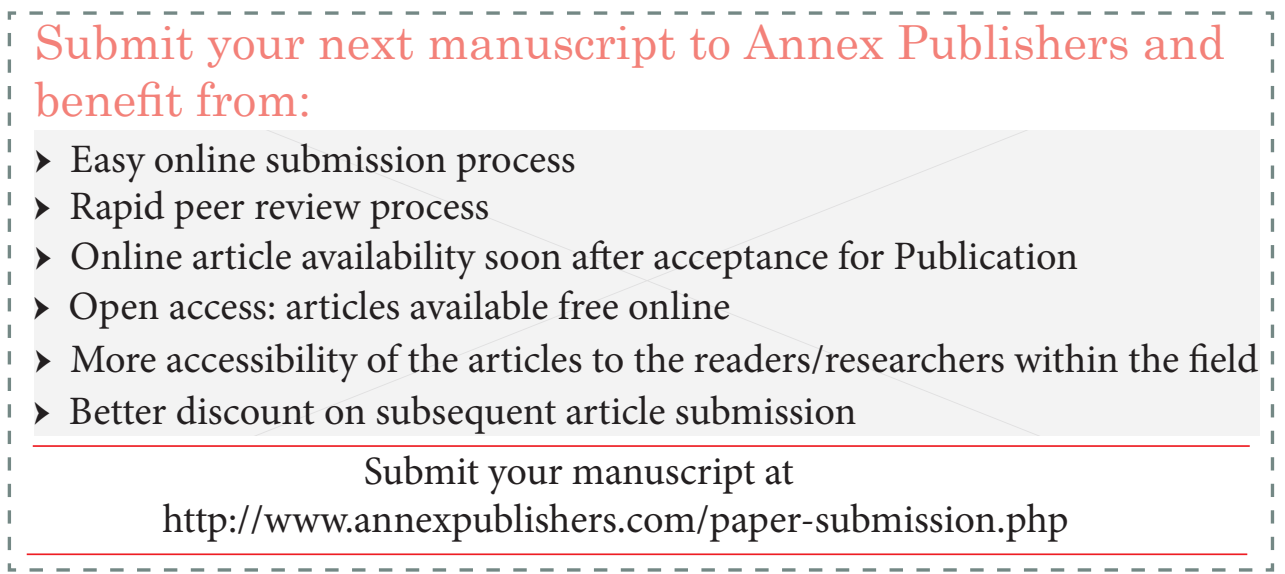

